\title{
Threat reduction assessment approach to evaluate impacts of landscape level conservation in Nepal
}

\author{
Ram Prasad Lamsal ${ }^{1 *}$, Bikash Adhikari ${ }^{1}$, Sanjay Nath Khanal ${ }^{1}$ and Khet Raj Dahal ${ }^{2}$ \\ ${ }^{1}$ Department of Environmental Science and Engineering, Kathmandu University, Nepal. \\ ${ }^{2}$ Department of Civil Engineering, Kantipur Engineering College, Tribhuvan University, Nepal.
}

Received 1 December, 2014; Accepted 31 December, 2014

\begin{abstract}
Major challenges to the landscape level conservation intervention are to monitor and evaluate the conservation impacts in an accurate and cost-effective manner. Threat reduction assessment (TRA) has been proposed as a method to measure conservation success and as a proxy measurement of conservation impacts and monitoring threats. We conducted TRAs to evaluate the effectiveness of Nepal's Terai Arc Landscape (TAL) program in mitigating threats to forests of seven corridor and bottleneck sites. We modified Margoluis and Salafsky (2001) framework and scoring approach and calculated TRA index. Threats were standardized to allow comparisons across the sites and effectiveness of management modes in reducing threats between the community-based management (CBM) and conventional government managed system (GMS). TRA index of CBM was significantly higher from those of GMS as evident by various parametric and non-parametric tests including principal component analysis. However, the TRA approach is not immune to bias as it depends on subjective analysis, but it could be a simple and cost-effective conservation monitoring tool to be easily implemented by local communities and stakeholders.
\end{abstract}

Key words: Terai arc landscape (TAL), threat reduction assessment (TRA), community based management (CBM), government managed system (GMS).

\section{INTRODUCTION}

Nepal is exceptionally rich in biodiversity; however, it has experienced enormous challenges in biodiversity conservation particularly in the Terai region (Wagley and Ojha, 2002). Over time, a high proportion of the Terai forests have been modified by cutting, cultivation, burning, grazing and other anthropogenic actions (Chakraborty, 1999; FAO, 2009) and many of these forests have been significantly reduced in quality and quantity over time. The main threats to the Terai's biodiversity are forest encroachment and land use conversion, illegal logging, forest fire, wildlife poaching, uncontrolled grazing, comercial mining and invasive species (World Wildlife Fund, (WWF), 2004; National Planning Commission (NPC), 2010; Sapkota, 2009).

Nepal has experienced a series of policies and strategies for the management of forests and conservation of biodiversity (Multi-stakeholder Forestry Program (MSFP), 2013; NPC, 2013). Recently, the landscape-based conservation approach has been adopted as an opportunity to scale up conservation initiatives (WWF, 2004); and Terai arc

${ }^{*}$ Corresponding author. E-mail: ramplamsal@gmail.com.

Author(s) agree that this article remain permanently open access under the terms of the Creative Commons Attribution License 4.0 $\underline{\text { International License }}$ 
landscape (TAL) programme, as the recent example, a very ambitious and long-term programme initiated to secure biodiversity conservation and sustainable development (NPC, 2010).

The TAL is part of an overall conservation strategy aimed at protecting the biodiversity both inside and outside protected areas. The various management interventions undertaken by the TAL program contribute to the emergence of a new agenda to improve the management and protection of species and ecosystems as well as people's livelihood (Baland and Platteau, 1996; Treves et al., 2005; Barbier and Burgess, 2001). Thus, search for common and efficient methodology or strategy for program improvement and change assessment is one of the priority concerns. Understanding of pressures and threats may form basis to design pragmatic regimes for the protection of biodiversity, assessment of performance and identify the changes (Haines-Young and Potschin, 2009).

Despite the challenge, complexity and time taking to determine the changes in conservation status of biodiversity, "biodiversity monitoring" and "biodiversity threat assessments" are the two main commonly used approaches currently in use to measure biodiversity impacts (GEF, $1998,2008)$. To address the challenges faced in implementing biological indicator approaches to measuring conservation impacts and using results for decision making (Noss, 1999), scientists have responded to the need for practical and meaningful measures of conservation impacts by developing the TRA method (Margoluis and Salafsky, 1999; Lindner, 2012).

The TRA method is a low-cost and practical alternative to high cost and time-intensive approach (Lindner, 2012). This is a measurement tool that provides useful information at an acceptable cost and complements biological indicator approaches to measure conservation success. The TRA approach to measure conservation success is based on three key assumptions (Margoluis and Salafsky, 1998): a) All biodiversity destructions are human-induced; b) All threats to biodiversity at a given site can be identified and c) Changes in all threats can be measured or estimated.

The TRA method identifies threats, ranks them based on the criteria and assesses the progress in reducing them (Rome, 1999). The threats reduction can be evaluated using qualitative or quantitative measures and can serve a monitoring tool and alternative method of measuring conservation impacts (Margoluis and Salafsky, 1998; Rome, 1999). The TRA begins by following the procedural approach developed by IUCN (1998), Mugisha and Jacobsen (2003), Okot (2011), Margoluis and Salafsky (1999) which involves:

a) Defining the project area and listing all direct threats present at the site;

b) Ranking each threat based on 3 criteria: area, intensity and urgency (area refers to the percentage of the habitats in the site that the threat affects, intensity refers to the impacts of the threat within the site and urgency refers to the immediacy of the threat). Out of total threats, the highest ranked threat for each criterion receives the highest score, and the lowest ranked threat receives the lowest score;

c) Adding up the scores across all three criteria for total ranking;

d) Determining the degree to which each threat has been met;

e) Calculating the raw score for each threat and multiplying the total ranking by the percentage calculated to get the raw score for each threat; and

f) Calculating the final threat reduction index score by adding up the raw scores for all threats, dividing by the sum of the total rankings, and multiplying by 100 to get the TRA index.

Landscape level conservation with CBM has been lauded as a better approach to manage different resource regime than conventional, top-down GMS. However, the CBM has been appreciated for its success to achieve conservation and livelihood goals (Roche, 2007; Aryal et al., 2012) and empirical data are already generated in providing its effectiveness. However, in Nepal, both the GMS and the CBM approach have been operating concurrently for a decade. This study evaluates and compares the ability of landscape level conservation to mitigate threats, at the two different management regimes of CBM and GMS, as a proxy measure of conservation success.

\section{Objectives and hypothesis}

This study firstly identifies pressures and threats to biodiversity in TAL and develop TRA index; secondly determines and compares the effectiveness of conservation interventions between CBM and GMS; and thirdly identifies the suitability of TRA method in monitoring and performance assessment at landscape conservation. Moreover, the study was designed to test two main hypotheses, which include: a) areas where CBMs are being implemented have reduced threats as compared to area of GMSs; and b) TRA method is appropriate for monitoring and measuring the performance and impacts.

\section{METHODOLOGY}

\section{Field sites}

TAL is a transboundary landscape between Nepal and India consisting of a total area of $23,199 \mathrm{~km}^{2}$ in Nepal with forest area of $14000 \mathrm{~km}^{2}$. Four corridors (Mohana-Laljhadi, Basanta, Khata and Barandavar) and three bottleneck areas (Mahadevpuri, Lamahi and Dovan) of TAL were selected for study. The seven intervention sites had a total of 341 community forests, 114 government and 56 civil society institutions, totaling 511, which were considered as the population (N). Field study was conducted in 2012 and 2013 by 
Table 1. Population and sample of respondent institutions.

\begin{tabular}{lcccccccc}
\hline \multirow{2}{*}{ Sites } & \multicolumn{2}{c}{ CFUGs } & \multicolumn{2}{c}{ Government staffs } & \multicolumn{2}{c}{ Civil Society groups } & \multicolumn{2}{c}{ Total } \\
\cline { 2 - 9 } & $\mathbf{N}$ & $\mathbf{n}$ & $\mathbf{N}$ & $\mathbf{n}$ & $\mathbf{N}$ & $\mathbf{n}$ & $\mathbf{N}$ & $\mathbf{n}$ \\
\hline Basanta & 105 & 30 & 32 & 28 & 13 & 9 & 150 & 66 \\
Khata & 49 & 15 & 9 & 8 & 4 & 4 & 62 & 27 \\
Mahadevpuri & 30 & 8 & 9 & 8 & 6 & 4 & 45 & 20 \\
Lamahi & 55 & 13 & 23 & 16 & 11 & 12 & 89 & 39 \\
Dovan & 35 & 9 & 7 & 7 & 5 & 4 & 47 & 21 \\
Mohana Laljhadhi & 52 & 11 & 22 & 15 & 8 & 7 & 82 & 36 \\
Barandabhar & 15 & 4 & 12 & 7 & 9 & 6 & 36 & 16 \\
Total & 341 & 90 & 114 & 89 & 56 & 46 & 511 & 225 \\
\hline
\end{tabular}

$\mathrm{N}=$ population size; $\mathrm{n}$ = sample size; one for Lamahi is added from district headquarters.

selecting 225 representatives, one per institution, (n), with sampling error of $5 \%$ using Cochran's sample size formula for categorical data collection. The sample size of each site was determined as proportionate to the population size of the site. Site sample sizes were determined by using Equation 1:

$$
n_{h}=\left(\frac{N h}{N}\right) \times n
$$

Where $\mathrm{n}_{\mathrm{h}}$ is the sample size for site $h, \mathrm{~N}_{\mathrm{h}}$ is the population size for site $h, \mathrm{~N}$ is total population size, and $\mathrm{n}$ is total sample size.

The participants were divided into three groups: Community forest user groups (CFUGs), $n=90$ ); Government staff, $n=89$ ); and Civil society groups, $n=46$ ) (Table 1 ). Civil society respondents were identified as forestry sector stakeholders comprising federations of community based forest management groups, NGOs, INGOs, political parties, user groups of other natural resource management and development groups, private sector, professional organizations, donors and indigenous leaders. All three groups belonged to the forestry sector working with rural communities.

\section{Methods}

Series of interviews and discussions elicited an array of perspectives and a large amount of information. Four sets of questions were given to the participants to understand threats as per their experiences and perceptions. Firstly, participants were given a list of possible risks to the forest and biodiversity and asked to respond by indicating their level of agreement or disagreement on a 5-point Likert scale starting from ' $1=$ strongly disagree' to ' $5=$ strongly agree'.

Secondly, they had to answer how worrisome they estimated each threat using the same Likert scale to their respective site based on the five principal risks for which they thought improved preventive and remedial measures are required. Thirdly, open questionnaire survey was supplemented by discussions and field visits about the risks perceived by respondent such as potentially damaging to forests and biodiversity.

Participants were asked to consider threats to habitat integrity, quality and ecosystem functioning while natural phenomena such as earthquakes were not considered threats. Participants ranked the threats based on the relative importance and their experiences. Ranking scales of 1 (minimum) to 5 (maximum) were used throughout the exercise and all threats were ranked along one continuum. Total sum score was computed after all the threats were ranked with score. The respondents were individually asked to award mark, based on their evaluation of the extent to which management efforts had mitigated the threats. The scores for each threat were discussed to reach a consensus about a realistic score for the success of the management approach. After the scoring and ranking exercise, total ranking scores were multiplied by the percentage of the threat met to get a raw score for each threat. The TRA index was computed as (Equation 2) (Margoluis and Salafsky, 1999):

$$
\text { TRA index }=\frac{\text { Sumof rawscore }}{\text { Sumof possible ranking }} \times 100
$$

Due to the proximity and topographical similarity between management modes CBM and GMS, it was possible to observe large differences in threat variables due to the social and management factors of the management categories of the forest area studied. Finally, the result obtained was presented and responses were received from field level government staff $(\mathrm{N}=37)$ regarding the assessment of TRA approach using the standard 5-point Likert scale: Strongly disagree $=1$; disagree $=2$; neutral $=3$; agree $=4$; and strongly agree $=5$.

\section{Variables}

The independent variables, the presumed causes, in this study were the characteristics of respondents and types of forest management modes in relation to threat mitigation as listed in Table 2

The dependent variables, the presumed effect of interest were the five priority threats which were assessed by using quantitative information as listed in Table 3 on both CBM and GMS.

\section{RESULTS}

\section{Demographic characteristics}

The sample largely mirrors the population and the respondents were well represented across the sites based on their size. Accordingly, site wise, highest number of 66 respondents, (29.33\%) was from Basanta corridor, while lowest number of 20 respondents, (8.9\%) was from Mahadevpuri bottleneck. Among the respondent categories, 90 respondents $(40 \%)$ were community representatives, 89 respondents (39.6\%) were government staffs and 46 respondents (20.4\%) were from civil society. 
Table 2. Independent variables.

\begin{tabular}{lllll}
\hline Name & Type $^{\star}$ & Explanation & Unit & Sources \\
\hline Site name & N & Name of sites (1 to 7) & Number & Office record \\
Forest name & N & Name of forests & Number & Office record \\
Respondent groups & N & 1= Community; 2= Government and 3= Civil society group & Number & Survey Design \\
Management modes & C & $\begin{array}{l}\text { 1= CBM (Community based management); } \\
\text { 2= GMS (Government managed system) }\end{array}$ & Number & Office record \\
\hline
\end{tabular}

Table 3. Dependent variables.

\begin{tabular}{llccl}
\hline Name & Variables & Type $^{*}$ & Unit & Sources \\
\hline Different & Listing of threat variables & O & Likert scale & Survey design \\
CTRI & Threat reduction in CBM & C & Percent & \\
GTRI & Threat reduction in GMS & C & Percent & \\
CTR1 & Encroachment and land use conversion in CBM & C & Percent & \\
CTR2 & Poaching and trade in CBM & C & Percent & \\
CTR3 & Forest fire in CBM & C & Percent & \\
CTR4 & Commercial mining in CBM & C & Percent & Office records and field verification with \\
CTR5 & Invasive species and grazing in CBM & C & Percent & map and questionnaire \\
GTR1 & Encroachment and land use conversion in GMS & C & Percent & \\
GTR2 & Poaching and trade in GMS & C & Percent & \\
GTR3 & Forest fire in GMS & C & Percent & \\
GTR3 & Commercial mining in GMS & C & Percent & \\
GTR5 & Invasive species and grazing in GMS & C & Percent & \\
\hline
\end{tabular}

${ }^{*} \mathrm{~N}=$ Nominal; $\mathrm{C}=$ continuous, $\mathrm{O}=$ ordinal.

Age is an important factor that influences the working ability of the respondents. Results of analyses of data collected for this study reveal that the major age group of the respondents was of the 31 - 40 years age group (44.4\%) followed by the 41 - 50 age group (28\%), the 20 30 age group (18.1\%) and the 51 - 60 years old group $(9.3 \%)$.

Education, as a major component of empowering people and means of enhancing human capital varied among the respondents. In terms of the educational attainments, $36 \%$ of respondents had a capacity of simply to read and write; $38.2 \%$ of respondents attained school; $23.1 \%$ had a college degree and $2.7 \%$ had higher educations. Gender of respondents is considered as one of the variables influencing the perception on local forest resources, and in this study approximately $61 \%$ respondents were male followed by $39 \%$ of female

respondents.

Patterning was also apparent in terms of respondents' socio-economic status. In terms of economic status, respondents indicated that they represented from high level $(20 \%)$, medium level (56\%) and lower level (20\%). Social inclusion analyses showed that Brahmin and Chettri together added up $44 \%$ of the total participants followed by $28.4 \%$ indigenous group, $17.8 \%$ Madhesi and 9.8\% Dalit community (Figure 1).

\section{Threats in TAL}

The threats were ranked based on value derived from Friedman test as a measure of non-parametric alternative to the one-way ANOVA with repeated measures to test for differences between groups when the dependent variable being measured is ordinal. The test statistics was found significant with $x^{2}{ }_{23}=1418.03$ and $p=0.000$. Out of a total of 24 threats, five primary and common threats to the biodiversity across the TAL area were identified as (a) encroachment and land use conversion, b) poaching and trade (timber, NTFP and wildlife), (c) forest fire, d) commercial mining and e) invasive species and grazing (Table 4).

Table 5 shows the Chi-square test result based on proportion of respondents identifying and agreeing on existing or potential severity of threats on their locations. In general, higher number of threats were found statistically significant $(p<0.05)$ with the some site-wise differences in: a) all five primary threats in Dovan bottlenecks were not statistically significant ( $p>0.05)$; $b$ ) threats of invasive species and grazing in $\operatorname{Khata}(\mathrm{p}=0.097)$ and poaching and trade in Mahadevpuri $(p=0.247)$; encroachment $(p=$ $0.056)$ and poaching and trade $(\mathrm{p}=0.113)$ in Barandavar were not significant. This reveals that the threats to biodiversity at a given site can be different depending on 


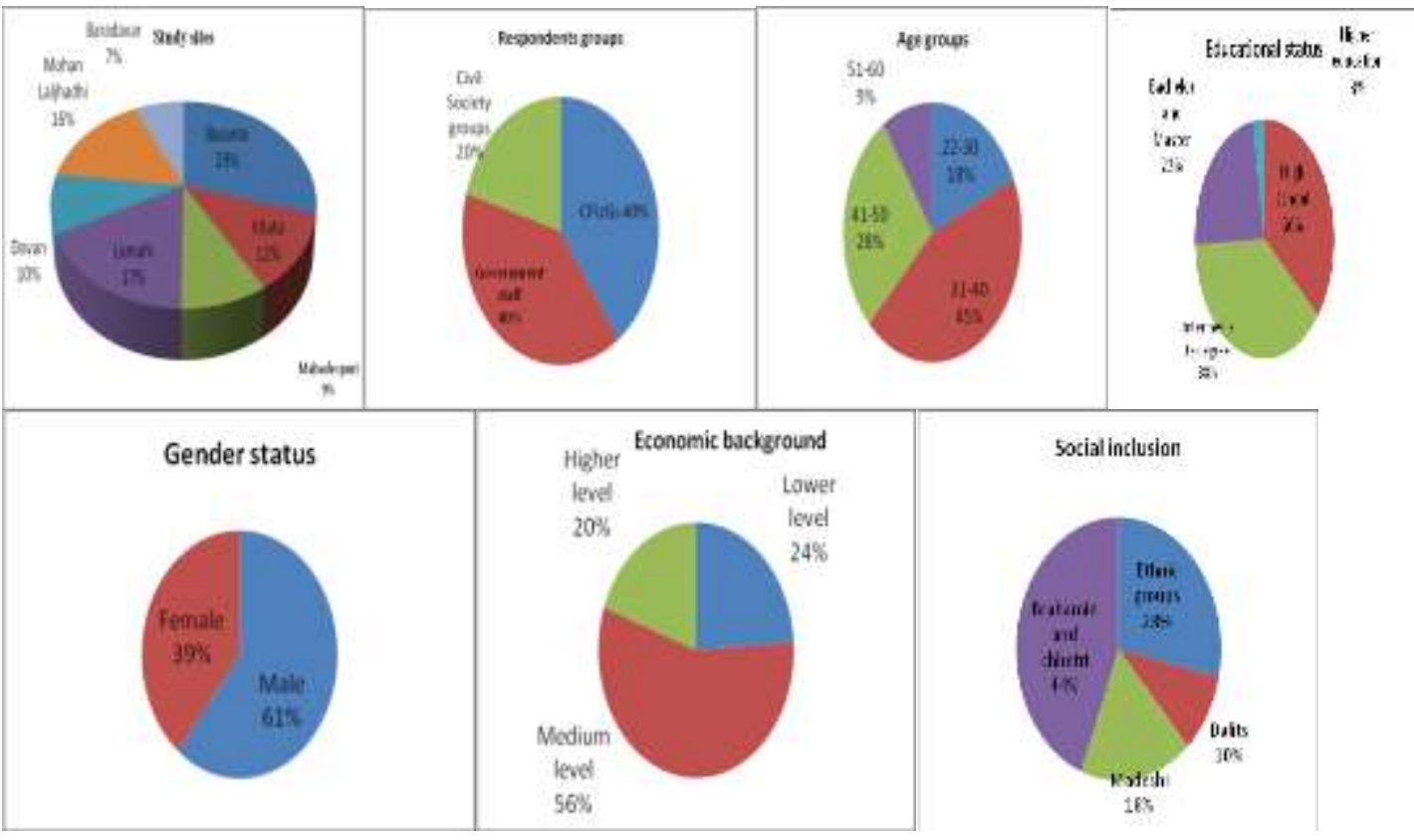

Figure 1. Demographic characteristics of the respondents (Source: field survey 2012 and 2013).

Table 4. Mean rank of threats based on Friedman test.

\begin{tabular}{llccll}
\hline S/N & Threats & $\begin{array}{c}\text { Mean } \\
\text { Rank }\end{array}$ & S/N & Threats & $\begin{array}{c}\text { Mean } \\
\text { Rank }\end{array}$ \\
\hline 1 & Encroachment and land use conversion & 22.57 & 13 & Land degradation and river cutting & 10.78 \\
2 & Poaching and trade) & 22.52 & 14 & Charcoal burning & 11.07 \\
3 & Forest fire & 18.82 & 15 & Poor management & 12.41 \\
4 & Commercial mining & 18.96 & 16 & Lack of manpower and budget & 11.34 \\
5 & Invasive species and grazing & 18.95 & 17 & Poor institutional capabilities & 12.55 \\
6 & Unclear boundaries & 11.58 & 18 & Community rights denied & 12.03 \\
7 & Highways and development projects & 13.32 & 19 & Bad community and staff relations & 11.47 \\
8 & Human wildlife conflicts & 11.52 & 20 & Lack of awareness & 12.49 \\
9 & Increased human population & 13.16 & 21 & Policy conflicts & 11.18 \\
10 & Political interference & 13.38 & 22 & Illiteracy & 12.44 \\
11 & Armed conflicts and insurgency & 11.58 & 23 & Poor law and order & 10.51 \\
12 & Fuel-wood sell & 13.24 & 24 & Corruption and poor governance & 12.11 \\
\hline
\end{tabular}

Source: Field survey, 2012.

nature and magnitude of direct threats and indirect threats. Therefore, assessing how much the threat had changed at landscape level since project implementation also required support of experienced respondents on identification, quantification and interpretation of site level data which has been often challenging.

\section{Reduction of primary threats}

Twenty four threats were identified at the entire seven study sites. The most frequently reported common threats in all sites of both CBM and GMS were forest encroachment and land use conversion followed by poaching; trade of timber, NTFP and wildlife; forest fire; commercial mining and non-human factors such as invasive species and livestock grazing.

Encroachment was a main reason of land use change in recent years that occurred in all study areas. However, the trend has been slowed or halted due to the landscape conservation intervention such as security of land tenure and access to resources for local people through CBM, strengthening protected area system and expansion of buffer zone. As shown in Table 7, this was the largest threats in terms of area, intensity, urgency and greatly reduced in CBM against GMS. The paired t test revealed 
Table 5. $X^{2}$ test result on site specific risk of primary threats.

\begin{tabular}{|c|c|c|c|c|c|c|c|c|c|c|c|c|c|c|c|}
\hline \multirow{3}{*}{ Sites } & \multicolumn{15}{|c|}{ Threats } \\
\hline & \multicolumn{3}{|c|}{$\begin{array}{l}\text { Encroachment and } \\
\text { land conversion }\end{array}$} & \multicolumn{3}{|c|}{$\begin{array}{c}\text { Poaching and } \\
\text { trade }\end{array}$} & \multicolumn{3}{|c|}{ Forest fire } & \multicolumn{3}{|c|}{ Commercial mining } & \multicolumn{3}{|c|}{$\begin{array}{c}\text { Invasive species } \\
\text { and grazing }\end{array}$} \\
\hline & $x^{2}$ & $\mathrm{n}$ & $\mathbf{P}$ & $x^{2}$ & $\mathrm{n}$ & $p$ & $x^{2}$ & $\mathbf{n}$ & $p$ & $x^{2}$ & $\mathbf{n}$ & $p$ & $x^{2}$ & $\mathrm{n}$ & $p$ \\
\hline Bas & 31.55 & 44 & 0.000 & 22.06 & 40 & 0.000 & 17.58 & 38 & 0.000 & 15.25 & 37 & 0.000 & 21.16 & 40 & 0.000 \\
\hline Khata & 9.56 & 16 & 0.008 & 16.22 & 18 & 0.000 & 6.89 & 14 & 0.000 & 6.89 & 14 & 0.032 & 4.667 & 14 & 0.097 \\
\hline Mahad & 12.40 & 14 & 0.02 & 2.80 & 10 & 0.247 & 6.70 & 12 & 0.035 & 9.80 & 15 & 0.007 & 16.30 & 15 & 0.000 \\
\hline Lamahi & 25.95 & 29 & 0.000 & 15.42 & 25 & 0.000 & 34.39 & 31 & 0.000 & 15.42 & 25 & 0.000 & 22.88 & 28 & 0.000 \\
\hline Dovan & 1.60 & 8 & 0.45 & 5.20 & 10 & 0.074 & 4.90 & 9 & 0.086 & 0.10 & 7 & 0.951 & 0.10 & 7 & 0.951 \\
\hline Laljhadi & 35.09 & 27 & 0.000 & 21.27 & 23 & 0.000 & 27.46 & 25 & 0.000 & 12.18 & 18 & 0.002 & 24.18 & 24 & 0.000 \\
\hline Barandavar & 5.765 & 10 & 0.056 & 4.353 & 9 & 0.113 & 1.53 & 8 & 0.000 & 7.882 & 11 & 0.019 & 18.47 & 14 & 0.000 \\
\hline
\end{tabular}

that the threat of encroachment has been found lower at CBM ( $\bar{x}=37.26 \pm 1.29)$ than GMS ( $\bar{x}=25.33 \pm 1.54)$ with difference of $\bar{x}=11.92 \pm 1.88\left(\mathrm{t}_{224}=6.324 ; \mathrm{p}=0.000\right)$ but it was still common in both.

CBM has reduced poaching including illegal logging and deforestation by creating local village level institutions. Local people conduct regular patrolling against illegal activities inside forest. The over extraction of flora and poaching of fauna diversity have been reduced (CBM, $\bar{x}$ $=37.97 \pm 1.05$ against the GMS, $\bar{x}=18.04 \pm 0.68$ ) resulting in difference of $\bar{x}=19.92 \pm 1.37$ and $\mathrm{t}_{224}=14.55 ; \mathrm{p}=0.000$ ). Interventions were created to combat the threats posed by poaching. This initiative was comprised of processes which address the complex and sensitive issues at local, national levels and was implemented in cooperation with the major stakeholders.

The traditional approach of focusing on legislation alone was not sufficient; and involving local communities were crucial to manage forest fires. Access to forest ownership have encouraged local participation and community based practices resulting in reduction in damaging and unwanted forest fires that led to more effective fire prevention and suppression. Legal obligations in fire management by government agencies have not been successful while local communities themselves were unable to manage intense and large fires. Nevertheless, awareness programs and community based forest fire management activities have been assisted by this program to manage forest fires. Result shows that the reduction of threats on fire was significant in CBM ( $\bar{x}$ $=37.00 \pm 1.04)$ when compared with GMS $(\bar{x}=18.11 \pm$ 0.68 ) with the difference of $18.89 \%$ and was statistically significant $\left(\bar{x}=18.89 \pm 1.33\right.$ with $\left.\mathrm{t}_{224}=14.13 ; \mathrm{p}=0.000\right)$.

Although collection, processing, transportation and trade of boulder, stone and sand have become a serious issue in biodiversity conservation, it has been reduced in CBM ( $\bar{x}=41.05 \pm 1.05)$ and in GMS ( $\bar{x}=16.51 \pm 0.73)$ $\left(\mathrm{t}_{224}=17.77 ; \mathrm{p}=0.000\right)$. Active community participation have gradually managed open grazing and invasive species particularly Mikania micrantha which have been widespread from east to west in Terai forests of Nepal which were significantly reduced in CBM $(\bar{x}=41.32 \pm 1.04)$ as compared to GMS $(\bar{x}=17.75 \pm 0.76) \quad\left(\mathrm{t}_{224}=17.16\right.$; $\mathrm{p}=0.000$ ) (Table 6).

\section{Threat reduction index}

Threat reduction analysis conducted showed that at all levels of area, intensity and urgency, forest encroachment and land use conversion represents the largest threat with a total average rank value of 12.3 , followed by poaching of timber and wildlife (rank value 9.49), forest fire (rank value 8.49), commercial mining (rank value 7.75 ), and invasive species and grazing (rank value 3.83). The extent of reducing threats differed between CBM and GMS. CBM illustrates reduction of threat with a range of 37.00 to $41.32 \%$, whereas GMS shows the range between 13.51 to $25.3 \%$ depending on specific threats.

Raw factor (percent threat reduction/100) and raw score (raw factor/total rank value) were used to estimate TRI. The result showed CBM with a total TRI of 38.47 with $10.32 \%$ in encroachment and land use conversion, $8.36 \%$ in poaching and trade, 6.94 in forest fire, 7.23 in commercial mining and 5.63 in invasive species and grazing. However, the GMS only showed a total TRI of only 19.31 with $6.96 \%$ in forest encroachment and land use conversion, $3.96 \%$ in poaching and trade, 3.36 in forest fire, 2.80 in commercial mining and 2.33 in invasive species and grazing (Table 7 ).

The TRI at CBM showed that there was significantly higher threat reduction than conventional GMS (mean difference of $19.16 \pm 1.238, t_{224}=15.74 ; p=0.000$ ). With reference to the overall performance of CBM and GMS, the ANOVA test revealed the difference at $p=000$ (CTRI, $F_{6,218}=41.596 ;$ and GTRI, F6,218 = 59.195)

\section{Principal component analysis (PCA) on major threats}

The results of the KMO measure of sampling adequacy 
Table 6. t-Test on comparing threats between CBM and GMS.

\begin{tabular}{lccccc}
\hline Comparisons & Mean difference & SE & t value & Df & Sig (2 tailed) \\
\hline CTR1 - GTR1 & 11.92 & 1.88 & 6.34 & 224 & .000 \\
CTR2 - GTR2 & 19.92 & 1.37 & 14.55 & 224 & .000 \\
CTR3 - GTR3 & 18.89 & 1.34 & 14.14 & 224 & .000 \\
CTR4 - GTR4 & 24.54 & 1.38 & 17.77 & 224 & .000 \\
CTR5 - GTR5 & 27.79 & 1.62 & 17.16 & 224 & .000 \\
\hline
\end{tabular}

Source: field survey, 2012.

Table 7. Threat reduction index.

\begin{tabular}{|c|c|c|c|c|c|c|c|c|c|c|c|c|}
\hline \multirow{2}{*}{ Threats } & \multicolumn{3}{|c|}{ Average value of threats* } & \multirow{2}{*}{ RV } & \multicolumn{4}{|l|}{ CBM } & \multicolumn{4}{|l|}{ GMS } \\
\hline & Area & Intensity & Urgency & & PTR & RF & RS & TRI & PTR & RF & RS & TRI \\
\hline Encroachment and land use conversion & 4.35 & 3.99 & 4.21 & 12.55 & 37.26 & 0.37 & 4.64 & 10.32 & 25.33 & 0.25 & 3.13 & 6.96 \\
\hline Poaching and trade (timber. NTFP and wildlife) & 3.45 & 3.02 & 3.43 & 9.9 & 37.97 & 0.38 & 3.76 & 8.36 & 18.04 & 0.18 & 1.78 & 3.96 \\
\hline Forest fire & 2.9 & 3.07 & 2.47 & 8.44 & 37.00 & 0.37 & 3.12 & 6.94 & 18.11 & 0.18 & 1.51 & 3.36 \\
\hline Commercial mining & 2.46 & 2.57 & 2.9 & 7.93 & 41.05 & 0.41 & 3.25 & 7.23 & 16.51 & 0.16 & 1.26 & 2.80 \\
\hline Invasive species and grazing & 1.84 & 2.35 & 1.99 & 6.18 & 41.32 & 0.41 & 2.53 & 5.63 & 17.75 & 0.17 & 1.05 & 2.33 \\
\hline Total & 15 & 15 & 15 & 45 & & & 17.31 & 38.47 & & & & 19.40 \\
\hline
\end{tabular}

*Measured in scale (1 to 5$)$ : Vey low, low and medium; RV = rank value $=$ area + intensity + urgency $; P T R=$ percent threat reduction; RF $=$ raw factor $=\mathrm{PTR} / 100 ; \mathrm{RS}=$ raw score $=\mathrm{RF} /$ total rank value; $\mathrm{TRI}=$ threat reduction index $=\mathrm{RS} /$ corresponding individual $\mathrm{RV}$.

Table 8. Rotated component matrix.

\begin{tabular}{lcc}
\hline & \multicolumn{2}{c}{ Components } \\
\cline { 2 - 3 } & $\mathbf{1}$ & $\mathbf{2}$ \\
\hline Eigen value & 4.27 & 3.14 \\
Variance explained & 42.7 & 31.4 \\
GTR3 & 0.969 & \\
GTR5 & 0.924 & \\
GTR2 & 0.910 & \\
GTR4 & 0.861 & \\
GTR1 & 0.604 & \\
CTR2 & & 0.880 \\
CTR3 & & 0.873 \\
CTR5 & & 0.841 \\
CTR1 & & 0.829 \\
CTR4 & & 0.778 \\
\hline
\end{tabular}

Extraction Method: principal component analysis; rotation method: Varimax with Kaiser normalization; a. rotation converged in 3 iterations.

revealed 0.791 and Bartlett's Test of Sphericity revealed a significance at a level of $0.000\left(X^{2}=2049.96, d f=45\right)$. Thus, the variables must be related to each other for the factor analysis to be appropriate. In order to examine underlying dimensions of the threat reduction, a factor analysis with a varimax rotation was performed. The results are presented in Table 8 with the factor at the level of 0.50 (or higher). Two factors emerged with Eigen values of 1.0 or higher. These two dimensions, explained $74 \%$ of the variance. The two underlying dimensions were labeled as follows: 1. Threats on GMS; and 2. Threats on CBM. In addition, reliability was performed on each of the two factors, based on the assessment items retained in each dimension.

Factor one, which is identified as GMS threats explained $42.70 \%$ of the variance with an Eigen value of 4.27 and a reliability coefficient of 0.83 . Factor two, which is labeled as threats on CBM, explained $31.3 \%$ of the variance with an Eigen value of 3.13 and a reliability coefficient of 0.78 . In the rotated factors, GTR1 to GTR5 all have high positive loadings on the first factor (and low loadings on the second), whereas CTR1 to CTR5 all have high positive loadings on the second factor (and low loadings on the first).

Factor loading from GMS ranged between 0.969 and 0.604 . Forest fire (0.969), invasive species and grazing (0.924), poaching and trade (0.910), commercial mining (0.861) and encroachment (0.604) were of great importance in the settlement of factor 1 of GMS. Similarly, factor loading from CBM ranged between 0.880 and 0.778 . Poaching and trade $(0.880)$, forest fire $(0.873)$, invasive species and grazing (0.841), encroachment (0.829) and commercial mining (0.778) outstandingly contributed to the formation of factor 2 in CBM.

\section{Analysis of additional threats}

Nineteen additional threats were identified as the threats 
Table 9. Comparing means of threats using McNemar test ( $d f=1$ ).

\begin{tabular}{lcccccc}
\hline \multirow{2}{*}{ Additional threats } & \multicolumn{5}{c}{ NF } & \multicolumn{5}{c}{ CF } & \multirow{2}{*}{ McNemar $\mathbf{X}^{2}{ }_{1}$} & $\mathbf{p}$ \\
\cline { 2 - 6 } & Yes & No & Yes & No & & \\
\hline Armed conflicts and insurgency & 158 & 67 & 131 & 94 & 20.7 & 0.000 \\
Bad community and staff relations & 73 & 152 & 55 & 170 & 27.40 & 0.000 \\
Charcoal burning & 67 & 158 & 33 & 192 & 36 & 0.000 \\
Poor law and order & 128 & 97 & 130 & 95 & 4.0 & 0.046 \\
Corruptions and poor governance & 96 & 129 & 110 & 115 & 4.55 & 0.033 \\
Fuelwood sale & 137 & 88 & 101 & 124 & 11.01 & 0.000 \\
Community rights restricted & 74 & 151 & 96 & 129 & 25.671 & 0.000 \\
Development projects & 155 & 70 & 171 & 54 & 31.36 & 0.000 \\
Human wildlife conflicts & 159 & 66 & 161 & 64 & 37.16 & 0.000 \\
Illiteracy & 152 & 73 & 154 & 71 & 27.04 & 0.000 \\
Increased population & 145 & 80 & 122 & 123 & 8.73 & 0.003 \\
Lack of awareness & 144 & 81 & 126 & 99 & 9.78 & 0.002 \\
Lack of manpower and budget & 128 & 97 & 114 & 111 & 1.37 & 0.242 \\
Land degradation and river cutting & 152 & 73 & 133 & 92 & 17.47 & 0.000 \\
Policy conflicts & 152 & 73 & 119 & 106 & 11,02 & 0.001 \\
Political interferences & 159 & 66 & 134 & 91 & 23.12 & 0.000 \\
Poor management & 102 & 123 & 113 & 112 & 0.42 & 0.520 \\
Unclear boundaries & 163 & 62 & 141 & 84 & 30.74 & 0.000 \\
Poor institutional capabilities & 127 & 98 & 101 & 124 & 0.045 & 0.830 \\
\hline
\end{tabular}

to sustainable management of resource. Comparison between CBM and GMS indicates significant differences in mitigation of additional threats. The specific threats identified and mitigated at different areas, however, offer a deeper understanding of conservation effectiveness. Closed questions with 3 options - yes, no, do not know were analyzed applying McNemar Chi Square test where "do not know "was taken closer to "no" and recoded as same variable and yes as the other. A $p$ value of $<0.05$ was taken as significant. The responses were compared between CBM and GMS and statistically significant threats as indicated by McNemar test (Table 9).

Statistically significant threats with $\mathrm{p}<0.05$ included: armed conflicts and insurgency; b) bad community and staff relations; $c$ ) community rights restricted $\mathrm{c}$ ) development projects; d) human wildlife conflicts; e) illiteracy; f) increased population; g) lack of awareness; h) land degradation and river cutting; i) policy conflicts; j) political interferences and k) unclear boundaries. Similarly, significant threats at marginal level were: a) poor law and order; b) corruptions and poor governance. However, statistically not significant threats at $p>0.05$ were: a) lack of manpower and budget $(p=0.242)$; b) poor management $(p=0.52)$ and $c)$ poor institutional capabilities $(0.83)$.

\section{Assessment of TRA method}

Reliability analysis was undertaken in order to understand whether the questions in this questionnaire all reliably measure the same latent variable (perception towards
TRA), a Cronbach's alpha was run on a sample size of 37 respondents and the value 0.801 which indicated a high level of internal consistency within the given scale was found. One sample median test showed the mixed results of the 10 response questions on assessment of TRA. The test with reference to value 2.5 and $50 \%$ cut point revealed a significant difference toward positive conclusion on its simplicity to use, easy to understand, useful, cost effecttiveness and replicable with $p=0.000$ and not positive conclusion on its accuracy $(p=0.324)$; training requirement $(p=0.099)$; and comparatively better $(p=0.099)$ (Table $10)$.

\section{Conclusion}

In general, TRA acts as useful tool for monitoring and evaluating conservation interventions, with specific weakness as it indirectly measures threats in biodiversity conservation. Despite the merits, biases could have occurred in the process of selecting the sites and respondents to participate in the survey and discussion. The results could be subjective and the scores for management performance may not be directly linked to specific intervention on biodiversity conservation.

The assessment highlighted that the potential for involving communities in monitoring trends in biodiversity should be integrated with biodiversity conservation. The results provided a current snapshot of the variety and severity of threats throughout the TAL conservation system. It involved key stakeholders in identifying threats 
Table 10. One sample median test on effectiveness of TRA method.

\begin{tabular}{|c|c|c|c|c|c|c|c|c|c|}
\hline & \multicolumn{3}{|c|}{ OP of category } & \multirow{2}{*}{$+/-$} & & \multicolumn{3}{|c|}{ OP of category } & \multirow{2}{*}{$+/-$} \\
\hline & $<2.5$ & $>2.5$ & $\mathbf{p}$ & & & $<2.5$ & $>2.5$ & $\mathbf{p}$ & \\
\hline Simple to use & 0 & 1 & .000 & + & No training required & 0.65 & 0.35 & .099 & - \\
\hline Easy to understand & 0 & 1 & .000 & + & Creates baseline & 0.08 & 0.92 & .000 & + \\
\hline Useful & 0 & 1 & .000 & + & Replicable & 0 & 1 & .000 & + \\
\hline Cost-effective & 0 & 1 & .000 & + & Apt for all scales & 0.11 & 0.89 & .000 & + \\
\hline Accurate & 0.59 & 0.41 & .324 & - & Comparatively better & 0.35 & 0.65 & .000 & + \\
\hline
\end{tabular}

$\mathrm{OP}=$ Observed proportion; test proportion $=50 \% ; \mathrm{p}=0.000$ for all; $+=$ positive and $-=$ negative weight.

and prioritizing problems from a multidisciplinary perspective and found that TRA approach could be used in TAL as a tool of monitoring and assessing impacts of conservation based on its scope and limitations.

In conclusion, the study findings indicated that the overall current management approaches under TAL fall short of addressing threats. Nevertheless, a trend in the data suggested that threats have been better and significantly mitigated at CBM as compared to GMS, indicating the CBM as a potentially more successful approach to conservation than the traditional top-down approach. It can therefore be concluded that CBM has performed better, as an approach to landscape conservation than the traditional top-down GMS. However, both approaches have not addressed all the threats which is expected.

\section{Conflict of interests}

The authors did not declare any conflict of interest.

\section{REFERENCES}

Aryal A, Brunton D, Shrestha TK, Koirala RK, Lord J, Thapa YB, Adhikari B, Ji W, Raubenheimer D (2012). Biological diversity and management regimes of the northern Barandabhar Forest Corridor: an essential habitat for ecological connectivity in Nepal. Trop. Conserv. Sci. 5(1):38-49.

Baland J, Platteau J (1996). Population Pressure and Management of Natural Resources: Income-sharing and Labor Absorption in Small scale Fisheries. FAO Economic and Social Development Paper. No. 139. Rome, Italy: Food and Agricultural Organization of the United Nations.

Barbier BE, Burgess JC (2001). The economics of tropical deforestation. J. Econ. Surv. 15(3):413-431.

Chakraborty RN (1999). Stability and outcomes of common property institutions in forestry: evidence from the Terai region of Nepal. Ecol. Econ. 36 (2001):341-353

FAO (2009). Nepal Forestry Outlook Study. Ministry of Forests and Soil Conservation Singha Durbar, Kathmandu, Nepal. Working Paper No. APFSOS II/WP/2009/05

GEF (1998). Guidelines for Monitoring and Evaluation for Biodiversity Projects. Global Environment Division, GEF/World Bank.

GEF (2008). GEF Impact Evaluation for GEF Protected Area Projects in East Africa. Impact Evaluation Information Document No. 12 September 2008.2 [Online] https://www.thegef.org/gef/sites/thegef.org/files/documents/lmpact_E val_Infodoc12 (Accessed 12 February 2013).
Haines-Young R, Potschin M (2009). Methodologies for defining and assessing ecosystem services. A research study. Centre for Environmental Management University of Nottingham, Nottingham.

IUCN (1998). Evaluating Effectiveness: A Framework for Assessing the Management of Protected Areas. Adrian Phillips, Series Editor, Best Practice Protected Area Guidelines Series No. 6, IUCN.

Lindner R (2012). Evaluating evaluation: Exploring evaluation methods to assist WWF-UK programme management. A thesis submitted in partial fulfillment of the requirements for the degree of Master of Science and the Diploma of Imperial College.

Margoluis R, Salafsky N (1999.). A Guide to threat reduction for conservation, Biodiversity Support Program, Washington, DC. [Online] www.worldwildlife.org/bsp/.../threat/tra.pdf [Accessed: 3 March 2012]

Margoluis R, Salafsky N (1998). Measures of success: Designing, managing, and monitoring conservation and development projects. Washington, D.C.: Island Press.

Margoluis R, Salafsky N (2001). Is Our Project Succeeding? A Guide to Threat Reduction Assessment for Conservation. Washington, DC, USA: Biodiversity Support Program.

MSFP (2013). National Forestry Sector Strategy Development (concept note), Multi-stakeholder Forestry Program, Nepal

Mugisha A, Jacobsen SK (2003). Threat reduction assessment of conventional and community-based conservation approaches to managing protected areas in Uganda. Department of Wildlife Ecology and Conservation, Program for Studies in Tropical Conservation, University of Florida.

Noss R (1999). Assessing and monitoring forest biodiversity: A suggested framework and indicators. For. Ecol. Manage. 115:131146

NPC (2010). Three Years Periodic Plan, Nepal

NPC (2013). Three Year Periodic Plan for 2013-2015, National Planning Commission, Government of Nepal

Okot JE (2011). An Ecological Assessment of Biodiversity Pressure in Mgahinga Gorilla National Park South Western Uganda. An unpublished MSc Thesis, University of Klagenfurt, Austria.

Roche R (2007). Livelihoods Approaches as a Conservation tools. University of Rhode Island.

Rome A (1999). Ecotourism Impact Monitoring: A Review of Methodologies and Recommendations for Developing Monitoring Programs in Latin America Ecotourism Technical Report Series 1, Alex C. Walker Foundation, The Nature Conservancy.

Sapkota IP (2009). Species diversity, regeneration and early growth of sal regeneration in Nepal: Responses to Inherent disturbance regimes, Doctoral Thesis, University of Agricultural Science, Alnarp.

Treves LN, Holland MB, Brandon K (2005). The Role of Protected Areas in Conserving Biodiversity and Sustaining Local Livelihoods. Annu. Rev. Environ. Resour. 30:219-52

Wagley M, Ojha H (2002) Analyzing Participatory Trends in Nepal's Community Forestry. Policy Trend Report 2002:122-142

WWF (2004). Terai Arc Landscape Strategy Plan (2004-2104), Ministry of Forests and Soil Conservation, Nepal. 